\title{
MICROSTRUCTURE AND MECHANICAL CHARACTERIZATION OF X70 STEEL WELDED JOINTS THROUGH HARDNESS MAPPING AND TENSILE STRENGTH TESTING
}

\begin{abstract}
In this paper, effects of preheating and type of electrode (E8010 and E8018) on microstructure and mechanical properties of 5L X70 steel welded joints were investigated. The microstructure of joint zone and fracture surface was analyzed by light optical microscope and scanning electron microscope equipped with energy dispersive spectroscopy. Hardness mapping and tensile test were also performed to find the relationship between microstructure and mechanical properties. The results showed a consistency between the hardness variation data and the microstructure of joint zone. Moreover, hardness mapping revealed coarse and fine grain subregions in the heat affected zone which were not detected in the micrographs. The tensile test indicated that the non-preheated sample, welded by cellulosic E8010, had the minimum value in the strength and the ductility of welded steel. The fractography also determined that size and distribution of strengthening phases affected the fracture mode of welded specimens.
\end{abstract}

Keywords: Hardness mapping, microstructure, steel X70, tensile strength

\section{Introduction}

With the increase of energy consumption in the recent years, pipeline steels have been developed due to their good toughness, high strength, superior weldability and sufficient deformation capacity [1-4]. Among the wide range of pipeline steels, API X70 is one of the most important steels extensively applied in oil and gas industries [5]. However, during fusion welding processes, the mechanical properties of X70 steel, especially in heat affected zone (HAZ), sharply deteriorate after experiencing a severe welding thermal cycle [6-8]. Therefore, a widespread interest has been taken by researchers to study joining process of X70 steel and optimize strength and toughness of the weld metal (WM) and the HAZ. For example, Li et al. [9-10] reported that with the cooling rate less than $1^{\circ} \mathrm{C} / \mathrm{s}$, the $\mathrm{HAZ}$ microstructure included polygonal ferrite, pearlite and a small amount of granular bainite while with the cooling rate of $10-20^{\circ} \mathrm{C} / \mathrm{s}$, granular bainite, lath bainite and polygonal ferrite appeared in the HAZ and as a result, weld toughness improved. Pouraliakbar et al. [11] used a neural network to predict HAZ hardness of X70 steel. Their results showed that the developed model can artificially be applied to estimate the effects of all input variables such as carbon equivalent and tensile test parameters on hardness distribution in the HAZ. Zhu et al. [12] studied mechanical properties of X70 welded joint with different $\mathrm{Ti} / \mathrm{N}$ ratios and found that the welds with near-stoichiometric ratio demonstrates the highest impact energy value. It is also revealed that a low intercritical reheat temperature $\left(810^{\circ} \mathrm{C}\right)$ led to the creation of austenite along the grain boundaries.

In many industrial applications, hardness values of the welds are applied as an acceptance criterion. Hence, hardness measurement of weld zone would be an important quality assurance test so that it can demonstrate whether the welding process with its parameters has met the requirements to achieve a sound joint [13]. According to the literatures [14-18], hardness mapping provides a qualitative view of strength heterogeneity in the weld zone and makes it possible to study the distribution of weld microstructure and mechanical properties. For instance, based on the hardness maps, Ren et al. [15] indicated that fracture path in the friction stir welded of aluminum alloys was compatible with the lowest hardness distribution. Ghazanfari and Naderi [16-17] used hardness mapping to investigate mechanical properties of HSLA steels during resistance spot welding process. Their results showed a good relation between the metallographic cross sections of welds and the hardness map. Moreover, Kavousi and Mirsalehi [18] analyzed the grain size distribution of the weld zone through the hardness mapping of the cross-section area of the welded samples. In this work, we tried to study fusion welding of X70 pipeline steel accurately and attain a reasonable relationship of hardness values with microstructure and mechanical properties of the joint zone.

\footnotetext{
FACULTY OF MINING AND MATERIALS ENGINEERING, AMIRKABIR UNIVERSITY OF TECHNOLOGY (AUT), TEHRAN, IRAN

Corresponding author: a.hamdollahzadeh@aut.ac.ir, arjanghamdollahzadeh@yahoo.com
} 
Chemical compositions of materials (wt. \%)

\begin{tabular}{|c|c|c|c|c|c|c|c|c|c|c|c|c|c|}
\hline \hline & $\mathbf{F e}$ & $\mathbf{C}$ & $\mathbf{N i}$ & $\mathbf{T i}$ & $\mathbf{S}$ & $\mathbf{P}$ & $\mathbf{C u}$ & $\mathbf{N b}$ & $\mathbf{M n}$ & $\mathbf{S i}$ & $\mathbf{V}$ & $\mathbf{N}$ & $\mathbf{C r}$ \\
\hline X70 & Bal. & 0.07 & 0.05 & 0.04 & 0.003 & 0.013 & 0.03 & 0.04 & 1.58 & 0.29 & 0.06 & 0.009 & 0.05 \\
\hline E8010* & Bal. & 0.1 & 0.2 & 0 & 0.03 & 0.015 & 0.12 & 0.01 & 0.54 & 0.2 & 0 & 0.001 & 0.01 \\
\hline E8018* & Bal. & 0.06 & 0.7 & 0.02 & 0.03 & 0.012 & 0.02 & 0.04 & 1.35 & 0.8 & 0.03 & 0.001 & 0.03 \\
\hline
\end{tabular}

* chemical compositions belong to the deposited metal

\section{Experimental Procedure}

The base metal used in this study was a $22-\mathrm{mm}$ thick $5 \mathrm{~L}$ X70 steel plate. The plates were welded by shielded metal arc welding (SMAW). Electrode E6010-2.4 mm was applied for root pass while E8010G-4 mm and E8018G-4 mm were used for subsequent passes (22 passes). Chemical compositions of parent metal and electrodes are listed in Table 1.

Firstly, the samples with thickness of $22 \mathrm{~mm}$ were fabricated by wire cut machine and the edges of plates were then ground to produce a V shape weld design. The prepared specimens were then welded using SMAW processing. It should be noted that preheating was done for two samples. Schematic of the weld specimens is illustrated in Fig. 1 and the welding parameters for each sample are given in Table 2 .

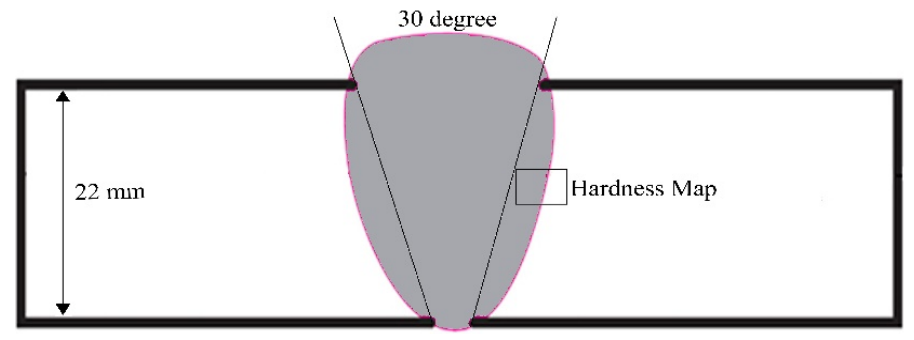

Fig. 1. Schematic of the weld specimens

TABLE 2

Welding parameters

\begin{tabular}{|c|c|c|c|c|}
\hline \hline $\begin{array}{c}\text { Sample } \\
\text { code }\end{array}$ & Electrode & $\begin{array}{c}\text { Welding } \\
\text { current (A) }\end{array}$ & $\begin{array}{c}\text { Welding } \\
\text { speed }\end{array}$ & $\begin{array}{c}\text { Preheating } \\
\left({ }^{\circ} \mathbf{C}\right)\end{array}$ \\
\hline S1 & E8010 & $185-195$ & - & 0 \\
\hline S2 & E8010 & $185-195$ & - & 100 \\
\hline S3 & E8018 & $170-180$ & - & 0 \\
\hline S4 & E8018 & $170-180$ & - & 100 \\
\hline
\end{tabular}

All the specimens were sectioned transversely, polished to $1 \mu \mathrm{m}$ diamond finish and then etched by $2 \%$ nital reagent. A light optical microscope (LOM) and TESCAN scanning electron microscope (SEM) equipped with electron dispersive spectroscopy (EDS) were applied to evaluate the microstructure of the welded samples. An image analyzer (Clemex software) was used to measure the mean grain size. The evaluation was performed at a magnification of $200 \mathrm{X}$ for a calibration factor of $0.320 \mu \mathrm{m} /$ pixel. 15 fields were analyzed on each specimen. Vickers hardness variation in the joint zone was obtained by an automatic hardness mapping machine with the load of $10 \mathrm{~N}$ and
$0.5 \mathrm{~mm}$ measurement interval. Surface hardness maps of 300 measured indents were then plotted for each sample. The location of hardness test was such a way that the weld zone, HAZ and base metal were placed in the map (see Fig. 1). Moreover, the tensile strength of specimens was assessed according to ASTM E8/E8M-08.

\section{Results and discussion}

\subsection{Microstructural evaluation}

The microstructure of X70 steel and the HAZ for all the specimens are illustrated in Fig. 2. As shown, base metal contains fine ferrite structure with a small amount of pearlite phase discontinuously placed in the high angle grain boundaries. According to the literatures, it is expected that a few martensite-austenite (M-A) constituents are also distributed along the ferrite grain boundaries [12]. The mean grain size of X70 steel is estimated about $4 \mu \mathrm{m}$. The microstructure of HAZ is completely different from the base metal because it experienced a thermal cycle during welding process. In addition to the change in microstructure, the grains in HAZ significantly grew. As shown in Fig. 2, the microstructure for S1 and S3 are similar. Both specimens includes fine quasi-polygonal ferrite, bainite and M-A constituents. The morphology of bainite is clearly determined in Fig. 3. Two different types of bainite structures, containing granular bainitic ferrite (lower bainite) and bainitic ferrite (upper bainite), were created in the HAZ which is due to the peak temperature values and the temperature fluctuation during welding process. It is suggested that the nucleation sites for bainite formation are located at the prior austenite grain boundaries and the apex of the formed bainitic ferrites [19]. It means that at the start of bainite transformation, nucleation sites along the prior austenite grain boundaries are engrossed to create bainitic ferrite structure. Also, new nucleation sites are produced at the apex of formed bainitic grains. Liu et al. [19] approved that the new generated nucleation sites are by far more than the primary occupied ones, hence, the number of nucleation sites enhanced with the formation of bainitic ferrite structure. Moreover, the bainite transformation temperature and reaction temperature range increase with increasing of heat input. So it can be revealed why the preheated samples are free from bainitic structure. In other words, S3 with lowest heat input (welding current density) would be the most susceptible specimen to form bainitic ferrite in the HAZ (see Fig. 3). As observed, with decrease in cooling rate, owing to 


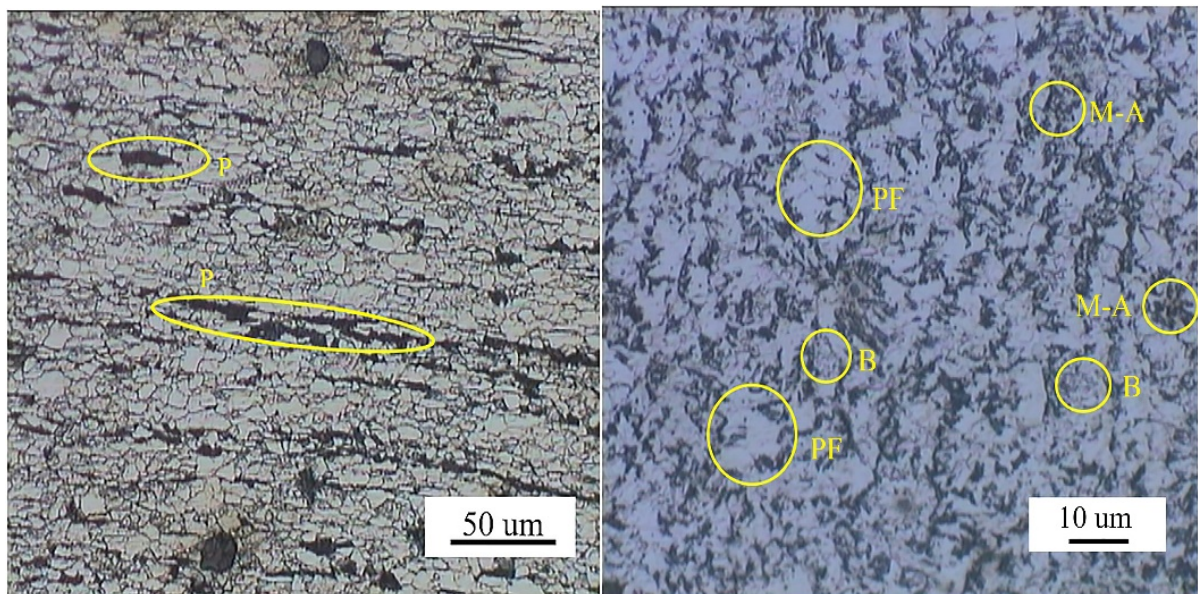

a b

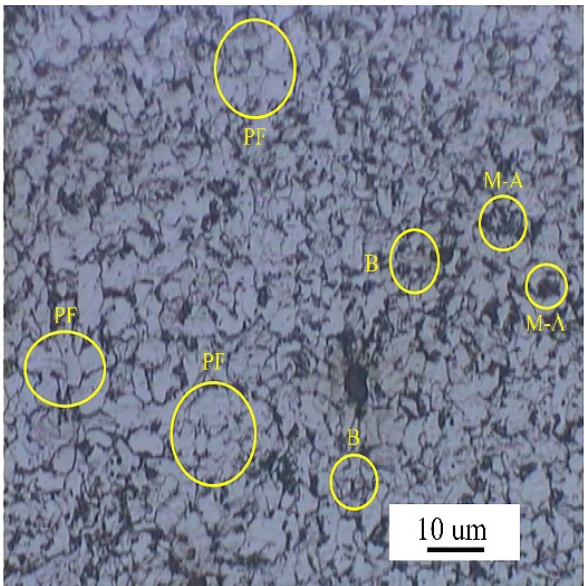

d

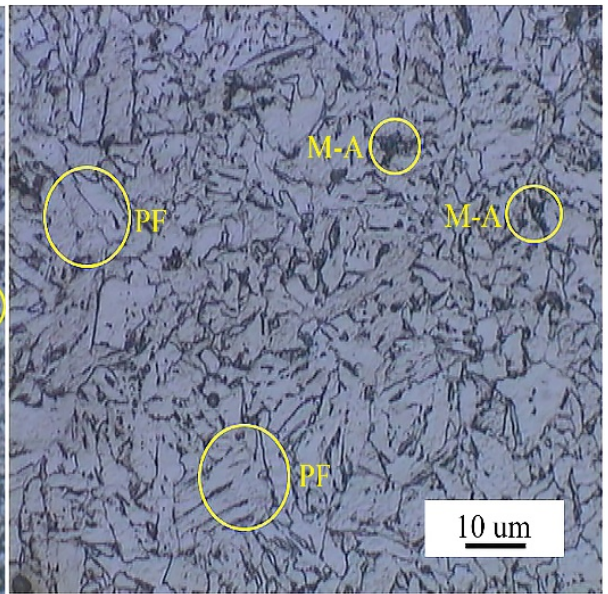

$\mathrm{C}$

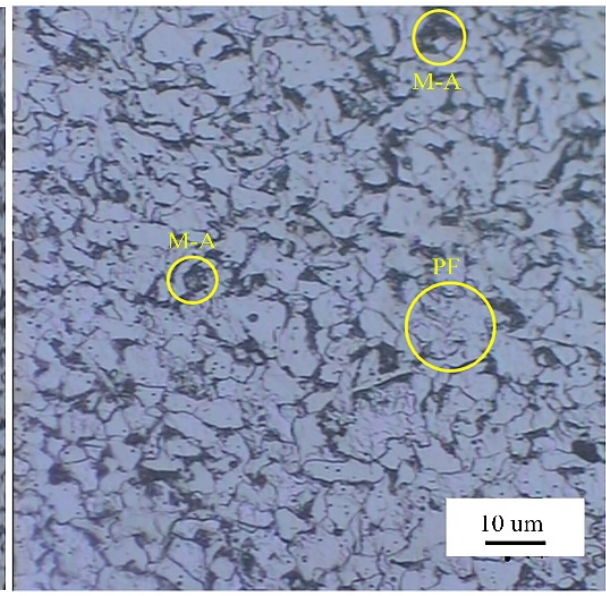

e

Fig. 2. Micrographs of a) base metal, $\mathrm{HAZ}$ in b) $\mathrm{S} 1$, c) $\mathrm{S} 2$, d) $\mathrm{S} 3$, e) $\mathrm{S} 4$, $(\mathrm{P}=$ pearlite, $\mathrm{B}=$ bainite, $\mathrm{PF}=$ polygonal ferrite, $\mathrm{M}-\mathrm{A}=$ martensiteaustenite constituents)

preheating, the HAZ microstructure in the samples S2 and S4 are distinct so that the mean grain sizes in these samples reached to 8 and $7 \mu \mathrm{m}$ which are much higher than that at S1 and S3 (6 and $5 \mu \mathrm{m}$, respectively). Furthermore, bainitic structure is removed from the HAZ, M-A constituents are considerably decreased and polygonal ferrite grains are apparently observed. Compared to $\mathrm{S} 3$ and S4, the HAZ microstructure in S1 and S2 is coarser and rougher because the heat input, resulted by current density, is higher than that of the samples welded by E8018 electrode (see Table 2). The microstructure of weld metals for all the samples is shown in Fig. 4. The optical micrographs indicate that acicular ferrite is the dominant phase in the weld microstructure. However, for the specimens influenced by preheating some other constituents are detected in the weld metal. It is believed that due to lower cooling rate in S2 and S4, the growth of grain boundary and polygonal ferrites is possible in the microstructure.

\subsection{Mechanical characterization}

Microhardness maps of samples welded by E8010 and E8018 are presented in Fig. 5. As an overall trend, the hardness

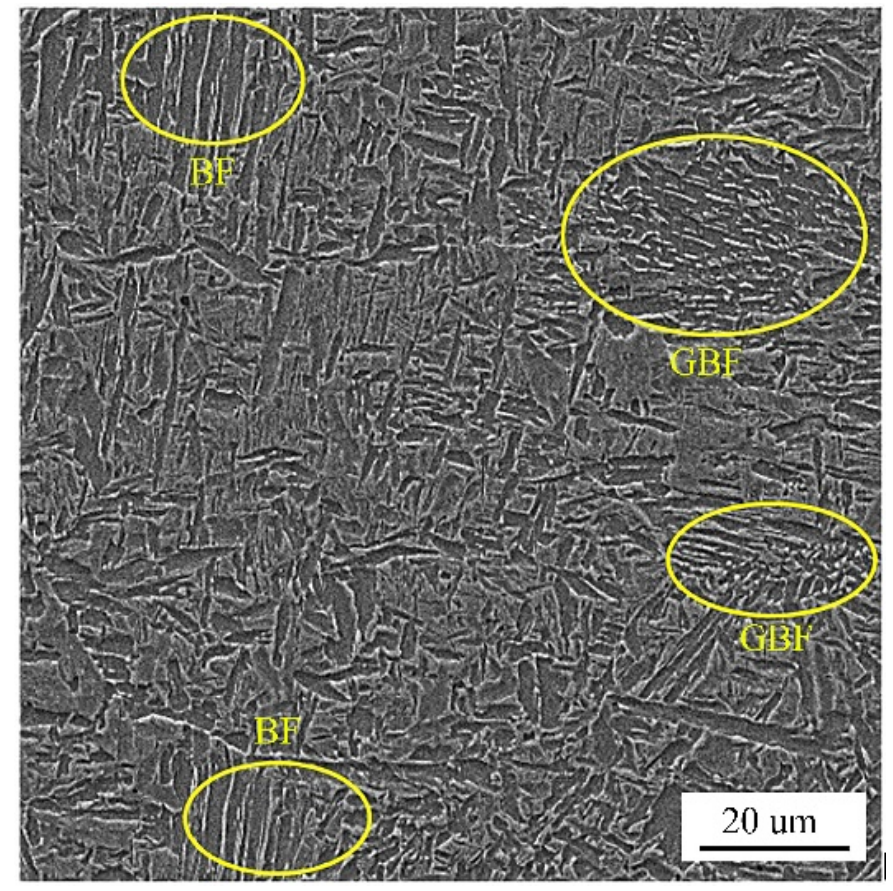

Fig. 3. Two types of bainite structure in the $\mathrm{HAZ}$ of $\mathrm{S} 3,(\mathrm{BF}=$ bainitic ferrite, $\mathrm{GBF}=$ granular bainitic ferrite) 


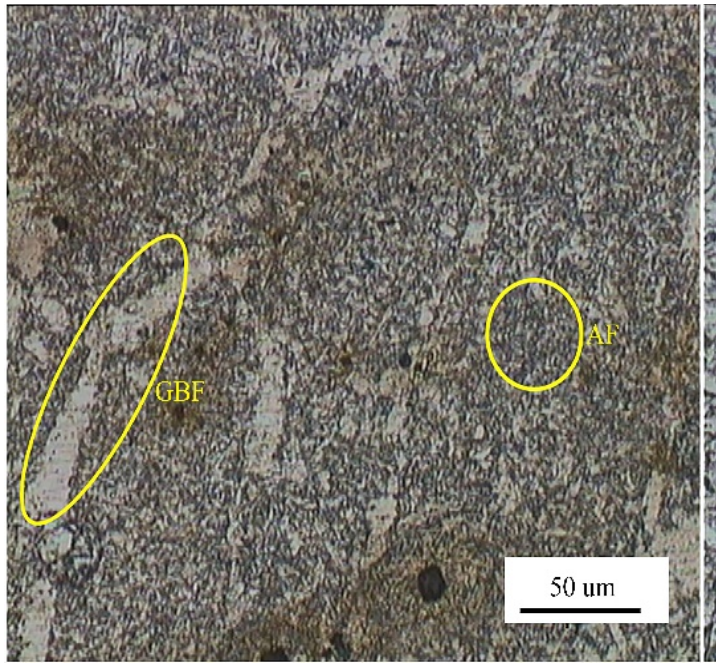

a

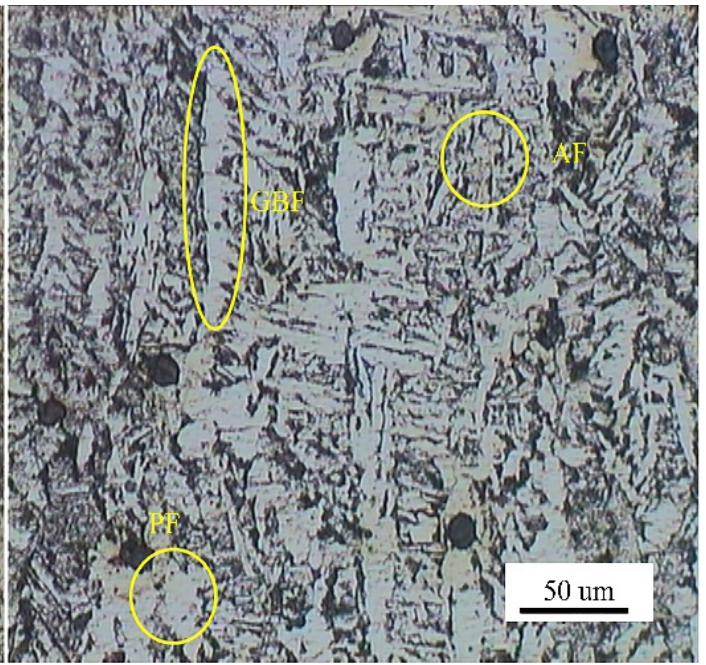

b

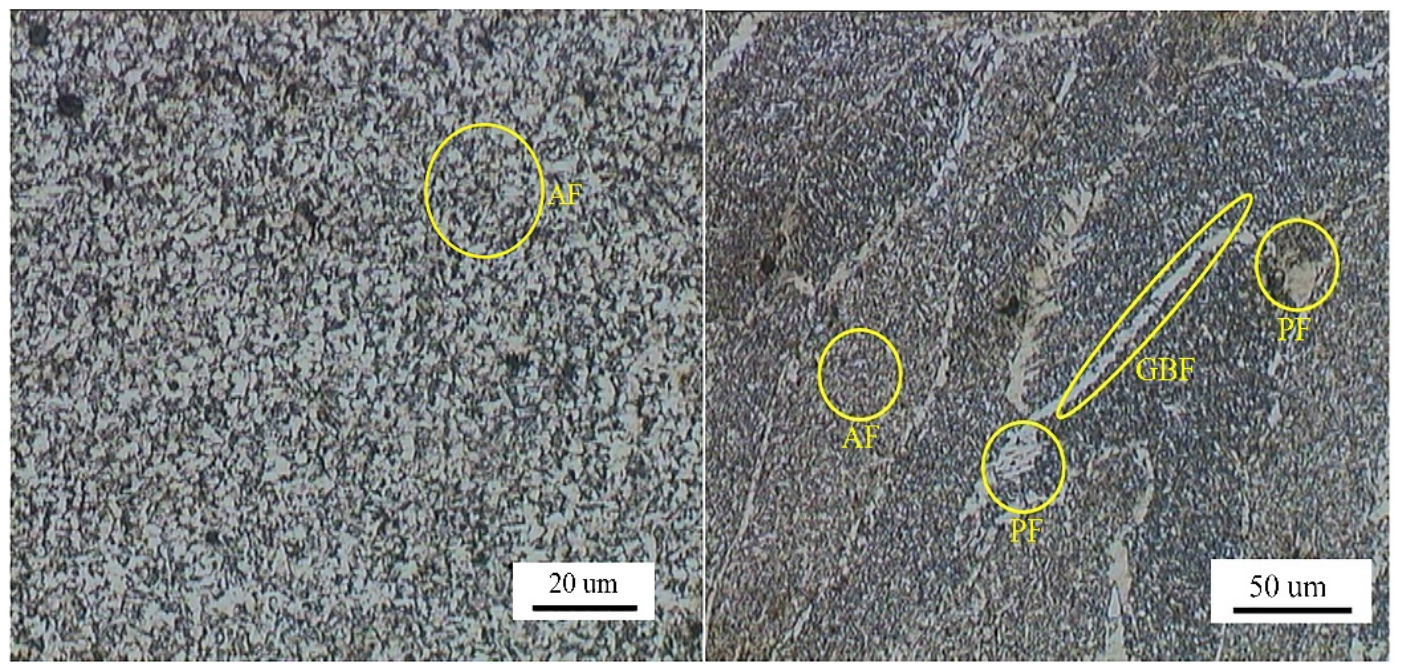

C

d

Fig. 4. Weld metal micrographs of a) $\mathrm{S} 1$, b) $\mathrm{S} 2$, c) $\mathrm{S} 3$, d) $\mathrm{S} 4,(\mathrm{GBF}=$ grain boundary ferrite, $\mathrm{PF}=$ polygonal ferrite, $\mathrm{AF}=$ acicular ferrite $)$

profiles indicate that the weld zone is divided into 3 distinct regions. The right side of the profiles defines X70 steel with hardness value of 220-230 VHN. Some small green regions with hardness value of $250-270 \mathrm{VHN}$ can be due to the presence of pearlite or M-A constituents along the ferrite grain boundaries. A drop in hardness is occurred by the formation of HAZ in the vicinity of base metal. It should be noted that the width of HAZ is different for each specimen. In general, the amount of heat input and preheating influence the HAZ width and its hardness. For the preheated samples (S2 and S4), the HAZ width is estimated about 7.1 and $6.2 \mathrm{~mm}$ while these values for $\mathrm{S} 1$ and $\mathrm{S} 3$ are just 1.8 and $1.4 \mathrm{~mm}$, respectively. Moreover, it is clear that the HAZ in preheated samples includes two distinguished subregions. Dark blue indicates coarse-grain HAZ (CGHAZ) with low hardness value (190-200 VHN) and light blue originates from fine-grain HAZ (FGHAZ) with higher hardness values. It is believed that widening of $\mathrm{HAZ}$ in preheated specimens led to the formation of CGHAZ and FGHAZ in the weld zone simultaneously, however, higher cooling rate in S1 and S3 prevents creation of extra CGHAZ at the weld metal/X70 steel interface.
Grain coarsening along with the formation of polygonal ferrite in HAZ of preheated specimens caused a slump in the hardness values. Non-preheated samples showed a narrow HAZ with high hardness distribution. Green and yellow spots in this part can be derived from a high-dislocation bainitic structure (see Fig. 3). It should be noted that the identification of subregions in HAZ was not possible by LOM while it was well detected using hardness mapping. The left side of the maps introduces weld metals for all the specimens. As observed, chemical composition of weld metal (electrode) and preheating led to the change in the microstructure and the hardness distribution of weld zone. The analyses show that the maximum hardness value belongs to the $\mathrm{S} 3$ and $\mathrm{S} 4(310 \mathrm{VHN})$ whereas for the $\mathrm{S} 2$, it is just in the range of 240-260 VHN. High hardness values in the weld metal can be attributed to the interwoven acicular ferrite, although, formation of grain boundary and polygonal ferrite made the hardness be decreased in some regions.

The stress-strain curves and detailed data for tensile strength testing are given in Fig. 6 and Table 3, respectively. The results indicate that the preheating process strongly affected the strength, 


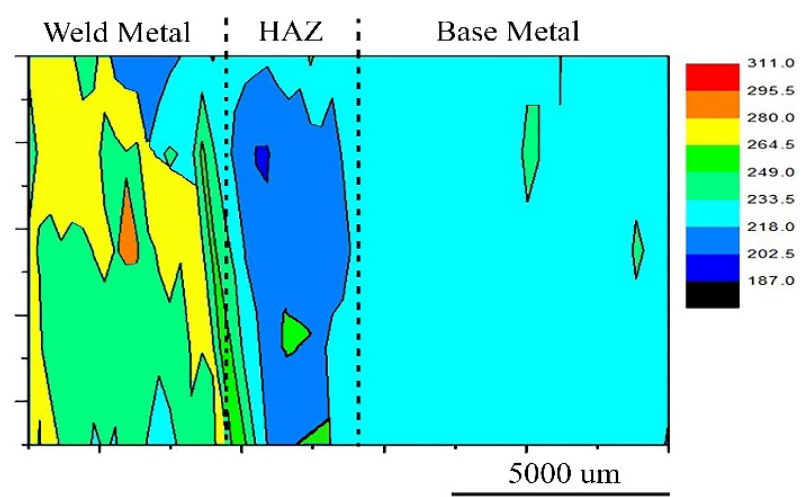

a

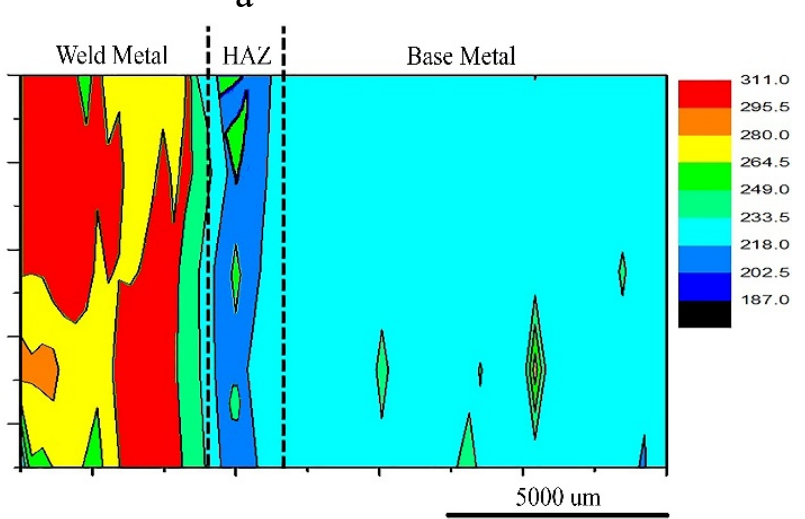

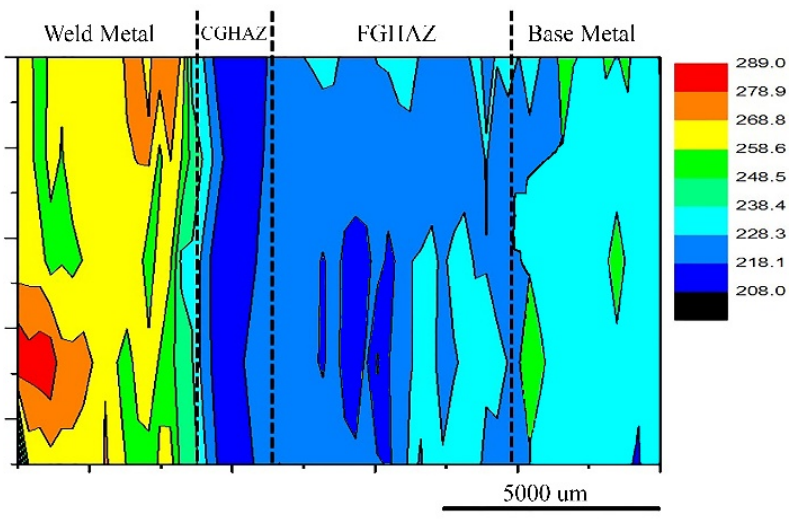

b

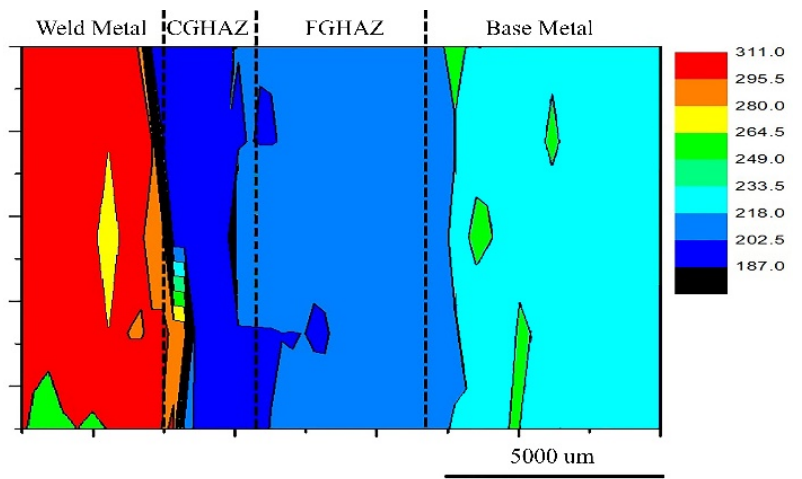

d

Fig. 5. Hardness maps of a) S1, b) S2, c) S3, d) S4

elongation and crack path of samples welded by E8010. The crack source in S1 confirms that the weld metal is the weakest region in the weld zone. It is considered using a cellulosic electrode (E8010) led to the hydrogen entry into the weld pool and the formation of brittle intermetallics in the joint zone [20]. For the preheated S2 and the samples welded by low-hydrogen electrode (E8018), the brittleness of welds dramatically reduced so that the elongation increased to $27-30 \%$. The Analyses proves our results so that the hydrogen content for $\mathrm{S} 1$ is more than $450 \mathrm{ppm}$ while this value is less than $60 \mathrm{ppm}$ for other samples.

TABLE 3

Detailed data for tensile testing

\begin{tabular}{|c|c|c|c|}
\hline \hline Sample code & $\begin{array}{c}\text { Tensile } \\
\text { strength (MPa) }\end{array}$ & Elongation (\%) & $\begin{array}{c}\text { Fracture } \\
\text { location }\end{array}$ \\
\hline S1 & 553 & 19 & Weld metal \\
\hline S2 & 560 & 27 & HAZ \\
\hline S3 & 581 & 30 & HAZ \\
\hline S4 & 574 & 28 & HAZ \\
\hline
\end{tabular}

Although the tensile strength values are different for these specimens, the fracture occurred through the HAZ. It indicates the HAZ is the weakest region for the crack propagation, however, it is feasible to improve mechanical properties by choosing proper welding parameters and consuming materials. The narrowest $\mathrm{HAZ}$ with fine grains were formed in $\mathrm{S} 3$ and as a result, the maximum strength value of $581 \mathrm{MPa}$ was achieved.

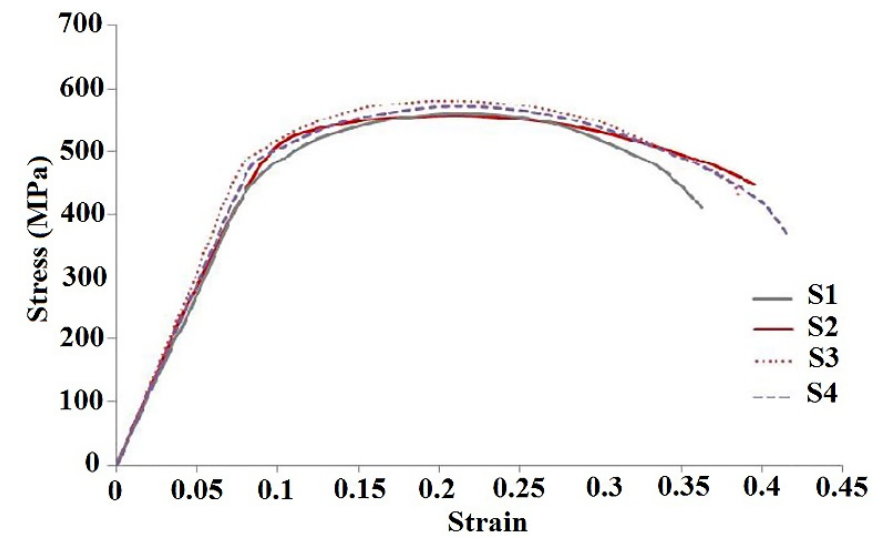

Fig. 6. Engineering stress-strain curves of welded samples

\subsection{Fractography}

Fracture morphologies of welded samples under tensile test are presented in Fig. 7. For S1 welded by cellulosic E8010, the fracture morphology shows a mixed mode of quasi cleavage and localized ductile dimple rupture. This pattern is consistent with low elongation of $\mathrm{S} 1$ during the mechanical test. The cleavage mode is also a proof for participation of hydrogen assistance cracking in the fracture mechanism of S1. For other samples, dimple structure is observed on the fracture surface. Two features distinguish these samples from each other; a) dimple size and b) distribution and size of strengthening phases. As clear, the 
dimple size for $\mathrm{S} 3$ is uniformly fine which is due to a ductile fracture during the tensile test. As mentioned before, the HAZ in S2 and S4 includes a considerable amount of polygonal ferrite. Hence, the crack can easily propagate through the HAZ while the bainitic ferrite structure leads to an increasing resistance to the crack propagation in the $\mathrm{HAZ}$ of $\mathrm{S} 3$. Another point should be noted is the presence of strengthening phases at the prior grain boundaries. The EDS analysis detected some complex Ti-rich carbonitrides $(\mathrm{Ti}, \mathrm{Nb}, \mathrm{V})(\mathrm{C}, \mathrm{N})$ on the fracture surface. Existence of this participate can be owing to the low free energy of TiN formation and relatively high diffusion coefficient of $\mathrm{N}$ and $\mathrm{Ti}$ in austenite [12]. A well-known relationship between the grain size and TiN is given $[12,21]$ :

$$
R=k \cdot(r / m)
$$

Where $k$ is the number factor relies on the particle type, $m$ is the volume fraction of particles, $R$ and $r$ are the size of grains and particles, respectively. This equation indicates that the small

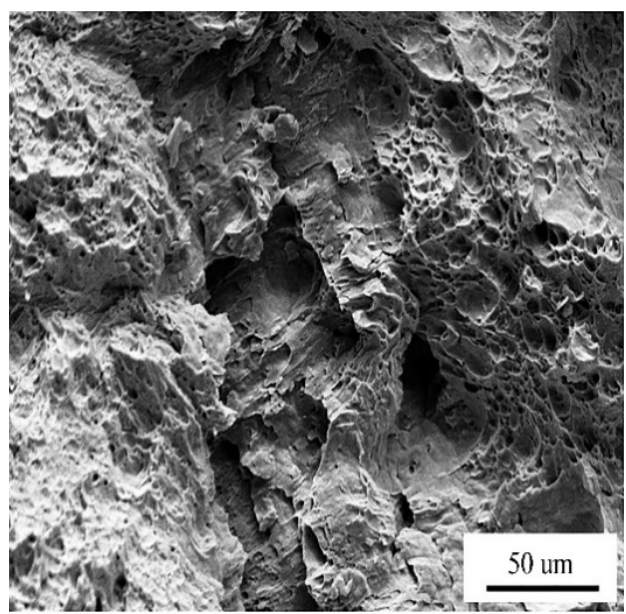

a

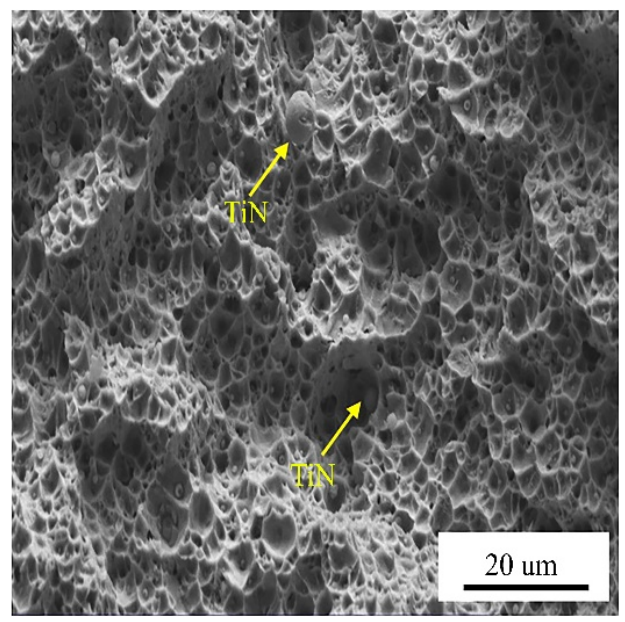

C

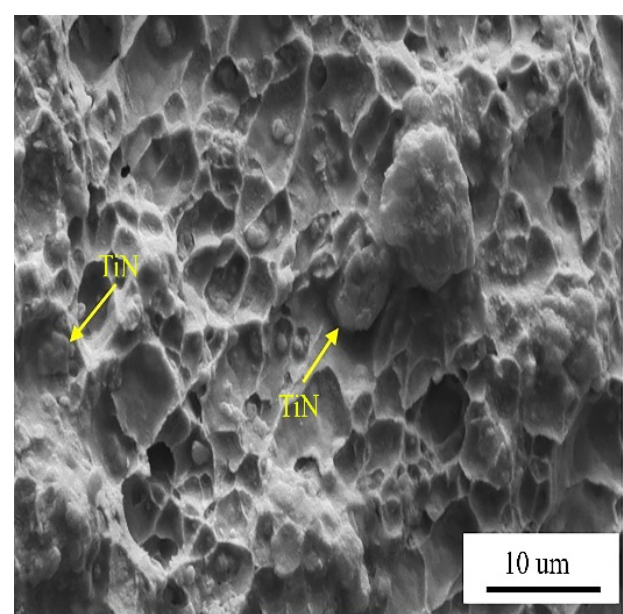

b

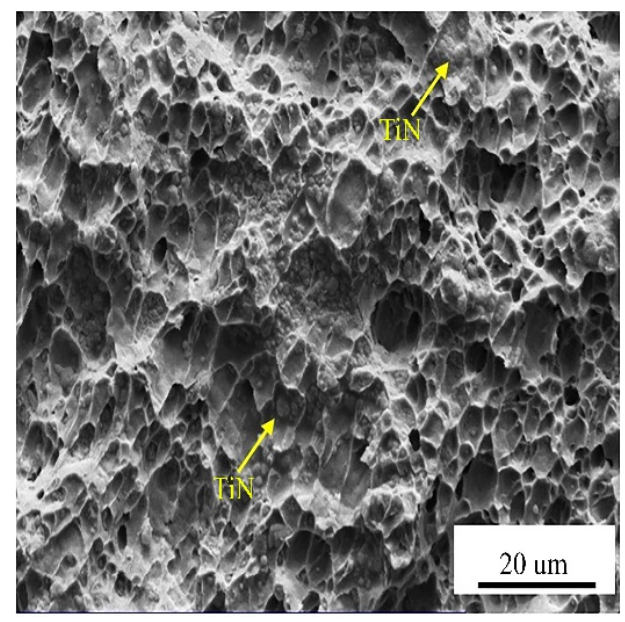

d

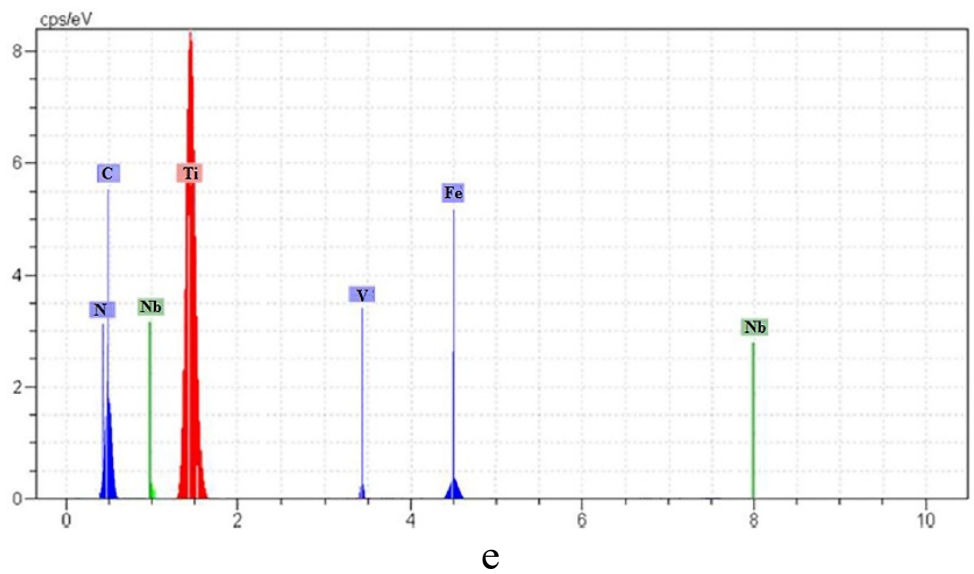

Fig. 7. Fracture surface of welded samples a) S1, b) S2, c) S3, d) S4, e) EDS spectrum for TiN (TiN in the SEM micrographs defines (Ti,Nb,V) $(\mathrm{C}, \mathrm{N})$ phases) 
grains has a straight correlation with the large volume fraction of small size TiN. So it can be concluded that for preheated samples (S2 and S4) with large grains in the HAZ, the TiN particles joined together and coarsened (see Fig. 7b and d) whereas they were finer and well distributed in S3.

\section{Conclusion}

In this work, microstructure and mechanical properties of pipeline steel welded joints by means of hardness mapping and tensile tests was investigated. The most significant findings of the present study are as follows:

1. Bainitic ferrite and M-A constituents and fine grain ferrites are the main structures in the HAZ of non-preheated samples while due to the low cooling rate in preheated ones, the HAZ contained coarse polygonal ferrite grains.

2. Two kinds of bainite structures, including granular bainitic ferrite and bainitic ferrite, were produced in the non-preheated HAZ which is owing to the temperature fluctuation and peak temperature values during welding process.

3. Hardness maps indicated that the HAZ consists of two subregions (coarse and fine grain zones) in the preheated samples whereas HAZ in non-preheated welded joints is monolithic and narrow.

4. The tensile test results revealed that the preheating process strongly influenced the strength, ductility and fracture mode of welded samples. The crack source in non-preheated specimen, welded by E8010, proved that the weld metal is the weakest region in the weld zone. However, the failure is occurred through the HAZ in other samples.

5. It is believed that dimple size and distribution of strengthening phases (TiN) can strongly affected the fracture mode of specimens so that for the sample with small dimples and well distributed precipitates, the strength and ductility values are optimum.

\section{REFERENCES}

[1] S. Hertelé, A. Cosham, P. Roovers, Eng. Struct. 124, 429-441 (2016).

[2] Y. Gu, P. Tian, X. Wang, X. Han, B. Liao, F. Xiao, Mater. Design. 89, 589-596 (2016).

[3] Y. Yang, L. Shi, Z. Xu, H. Lu, X. Chen, X. Wang, Eng. Fract. Mech. 148, 337-349 (2015).

[4] J.W. Sowards, T. Gnäupel-Herold, J.D. McColskey, V.F. Pereira, A.J. Ramirez, Mater. Design. 88, 632-642 (2015).

[5] B. Maamache, M. Bouabdallah, A. Brahimi, Y. Yahmi, B. Cheniti, B. Mehdi, Acta. Metall. Sin. 29, 568-576 (2016).

[6] Z. Zhu, L. Kuzmikuva, H. Li, F. Barbaro, Metall. Mater. Trans. B 45B, 229-235 (2014)

[7] V. Olden, A. Alvaro, O.M. Akselsen, Int. J. Hydrogen Energ. 37, 11474-11486 (2012).

[8] G. Khalaj, M. Khalaj, Int. J. Pres. Ves. Pip. 145, 1-12 (2016).

[9] C. Li, Y. Wang, Y. Chen, J. Mater. Sci. 46, 6424-6431 (2011).

[10] C. Li, Y. Wang, T. Han, B. Han, L. Li, J. Mater. Sci. 46, 727-733 (2011).

[11] H. Pouraliakbar, M. Khalaj, M. Nazerfakhari, G. Khalaj, J. Iron. Steel Res. Int. 22, 446-450 (2015).

[12] Z. Zhu, J. Han, H. Li, Mater. Design, 88, 1326-1333 (2015).

[13] J. Cho, S. Han, C. Lee, Mater. Lett. 180, 157-161 (2016).

[14] F.C. Liu, Z.Y. Ma, Metall. Mater. Trans. A39A, 2378-2388 (2008).

[15] S.R. Ren, Z.Y. Ma, and L.Q. Chen, Scripta Mater. 56, 69-72 (2007).

[16] H. Ghazanfari, M. Naderi, Acta Metall. Sin. (Engl. Lett.) 26, 635640 (2013).

[17] H. Ghazanfari, M. Naderi, Int. J. Miner. Metall. Mater. 21, 894897 (2014).

[18] A. Kavousi Sisi, S.E. Mirsalehi, Sci. Technol. Weld. Joi. 21, 43-52 (2016).

[19] C. Liu, X. Di, C. Chen, X. Guo, Z. Xue, J. Mater. Sci. 50, 50795090 (2015)

[20] M. Mosallaee, J. Hydari, S. Ghassemy, A. Mashreghee, Int. J. Pres. Ves. Pip. 111, 75-81 (2013).

[21] S. Matsuda, N. Okumura, Trans. Iron Steel Inst. Jpn. 18, 198-205 (1978). 